Supporting Information

\title{
Gradient and dynamic hydrogel materials to probe dynamics in cancer stem cell phenotypes
}

\author{
Junmin Lee ${ }^{1,2^{*}}$, Amr A. Abdeen ${ }^{1}$, Yanfen Li ${ }^{3}$, Shamalee Goonetilleke ${ }^{1}$, Kristopher A. \\ Kilian ${ }^{1,3,4^{*}}$
}

\begin{abstract}
${ }^{1}$ Department of Materials Science and Engineering, University of Illinois at UrbanaChampaign, Urbana, IL 61801

${ }^{2}$ Terasaki Institute for Biomedical Innovation, Los Angeles, CA 90064

${ }^{3}$ Department of Bioengineering, University of Illinois at Urbana-Champaign, Urbana, IL 61801

${ }^{4}$ School of Chemistry, School of Materials Science and Engineering, Australian Centre for NanoMedicine, University of New South Wales, Sydney, NSW 2052

*Correspondence to: jlee@,terasaki.org and k.kilian@unsw.edu.au
\end{abstract}



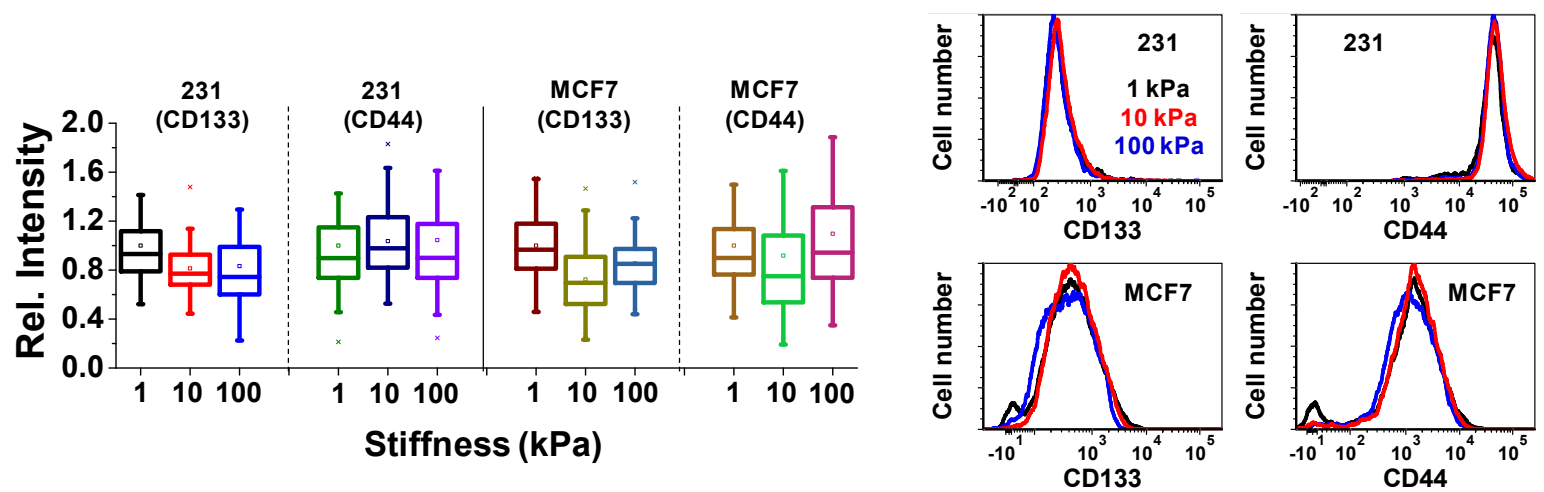

Figure S1. Expression of CSC markers (immunofluorescence \& flow cytometry) for breast cancer cells $(\mathrm{MCF} 7 \& 231)$ cultured on static substrates with different matrix rigidity $(1,10$, $100 \mathrm{kPa}) .(\mathrm{N}=3)$ 
231_Breast cancer cell line
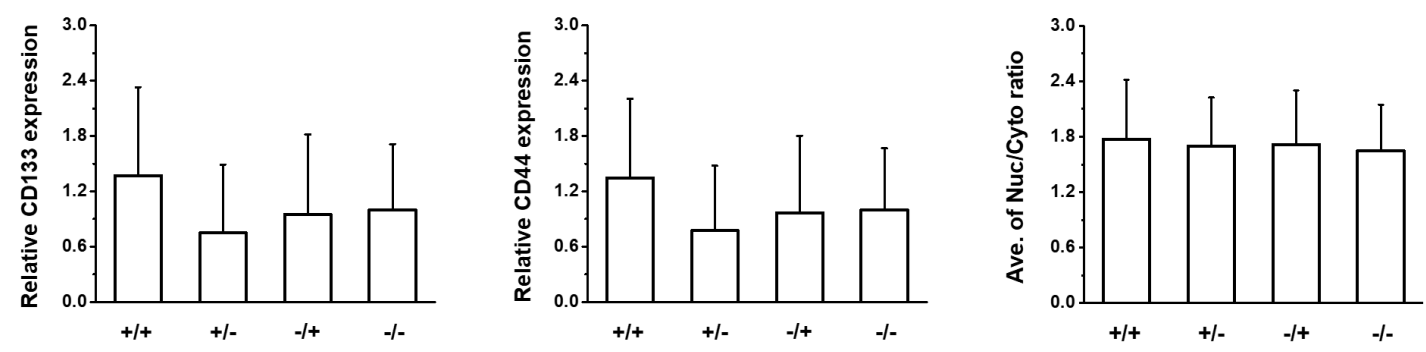

MCF7_Breast cancer cell line
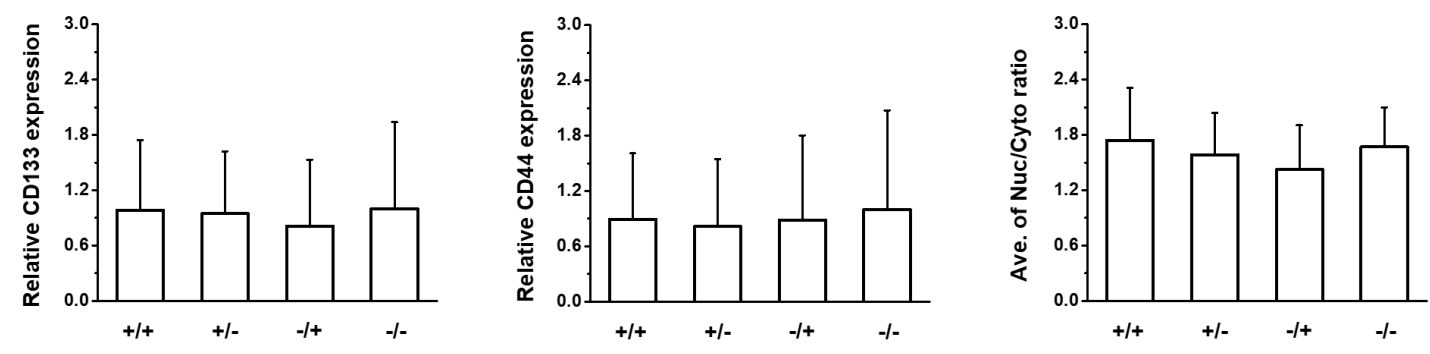

Figure S2. Relative expression of CSC markers (CD133 \& CD44) for breast cancer cells (MCF7 \& 231) cultured on dynamic gels. $(\mathrm{N}=3)$ 


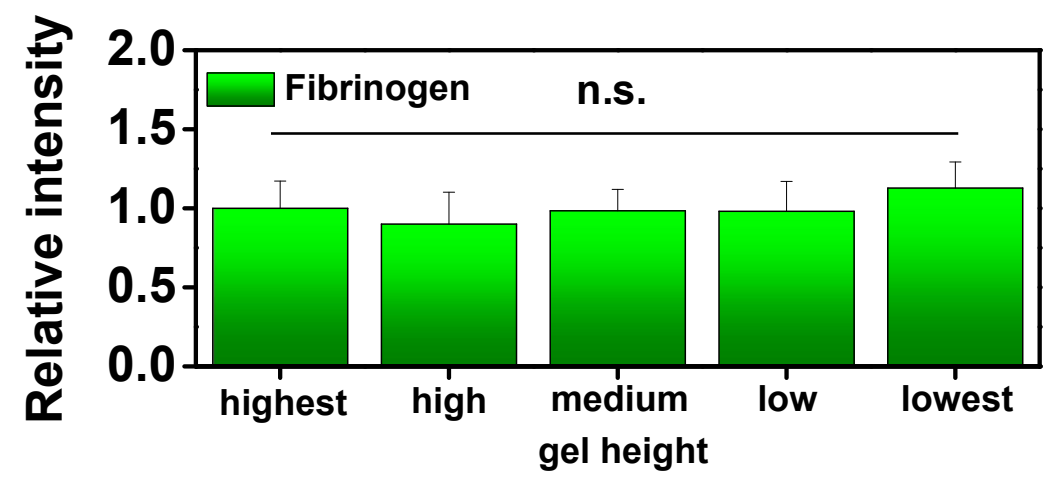

Figure S3. Relative intensity of FITC-fibrinogen patterned on gradient gels. 


\section{MCF7_Breast cancer cell line}

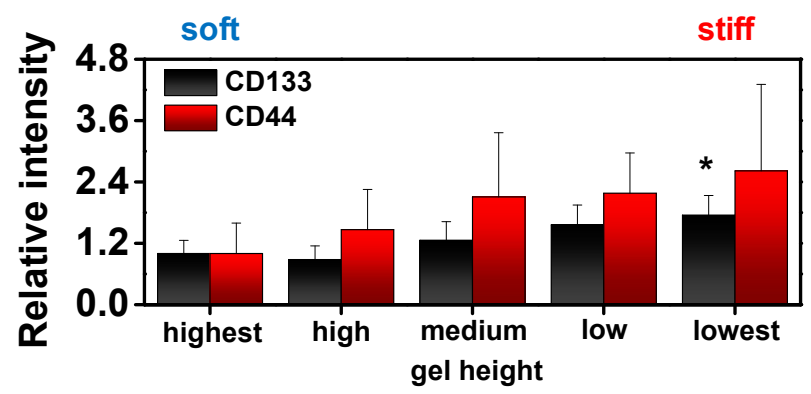

231_Breast cancer cell line

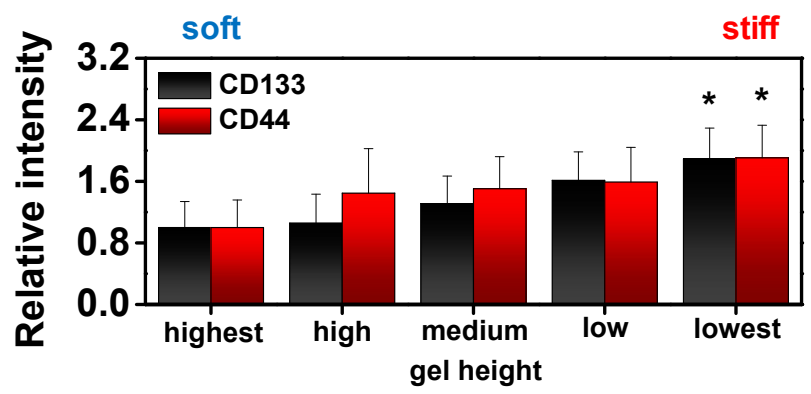

Figure S4. Relative CD133 and CD44 markers intensity of breast cancer cells cultured on stiffness gradient gels. ${ }^{*} P<0.05(\mathrm{~N}=3)$ 

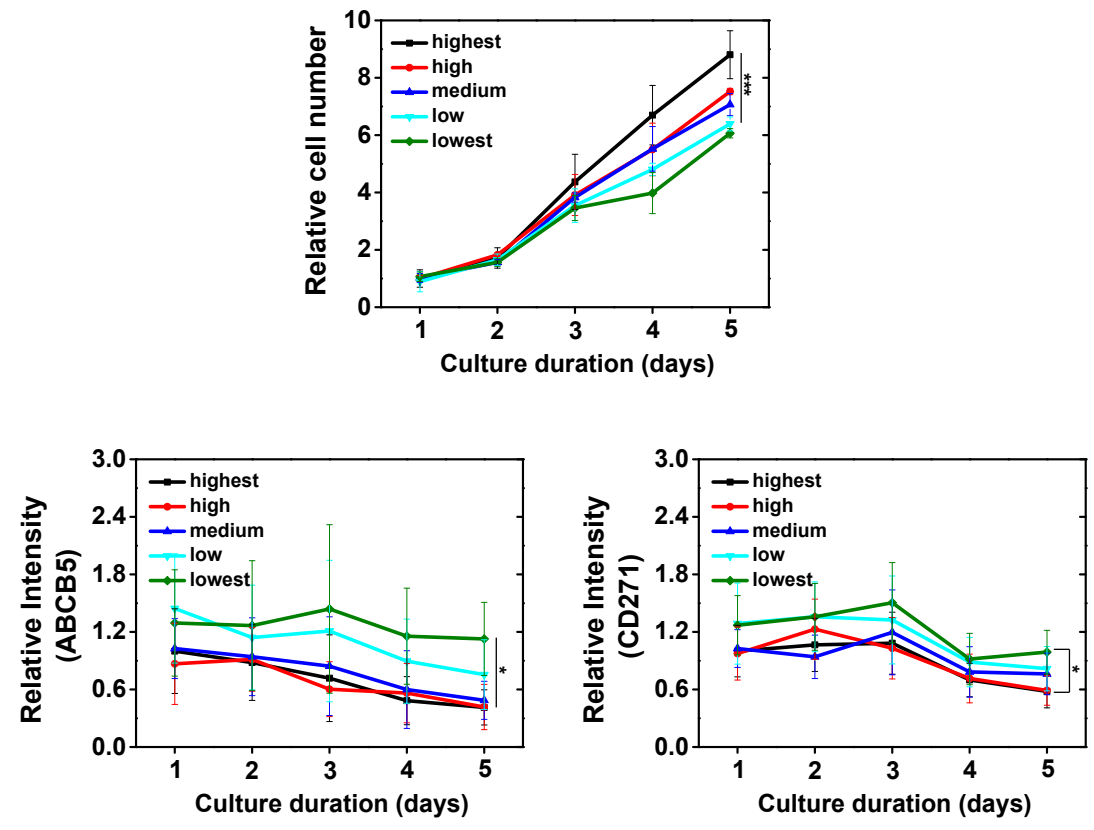

Figure S5. Relative cell number and CSC marker expression (ABCB5 \& CD271) for B16F0 cells cultured on stiffness gradient gels. $(\mathrm{N}=3)$ 

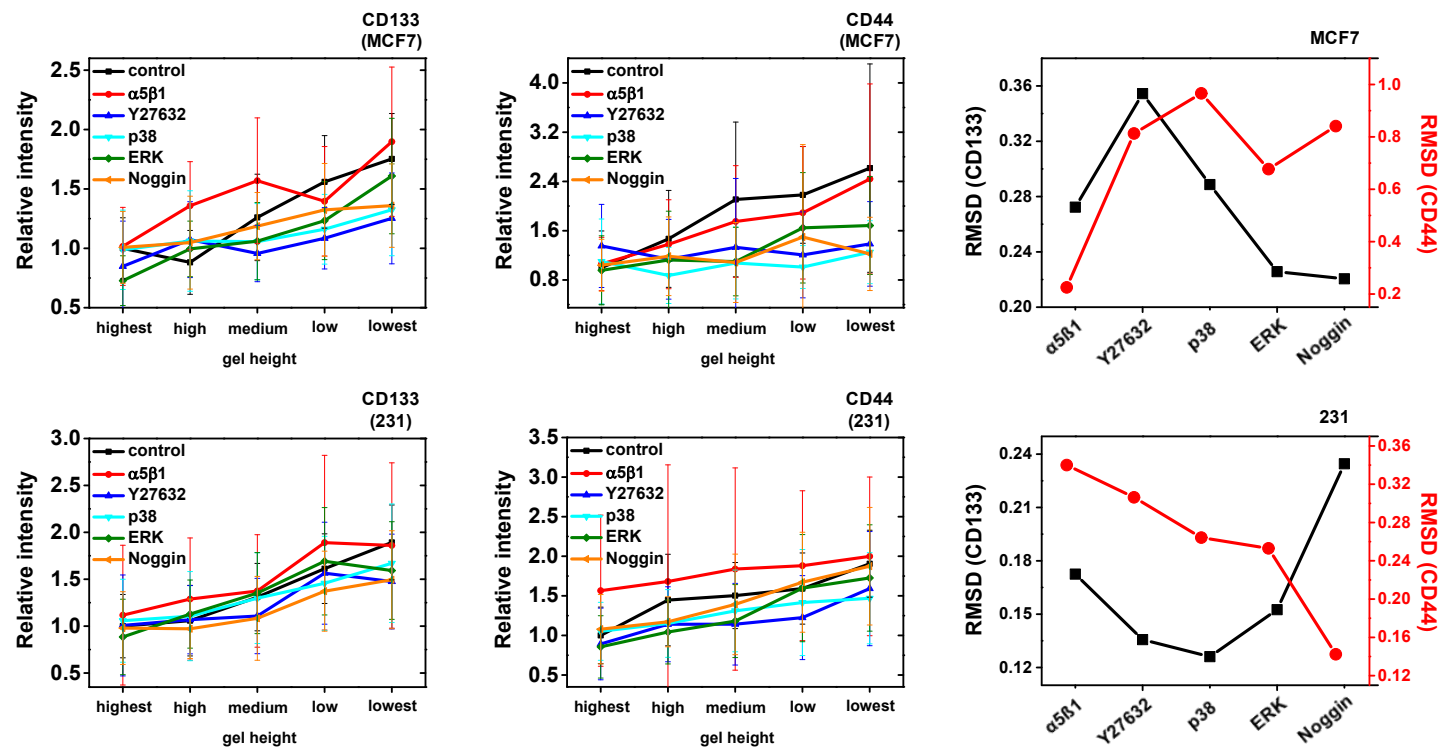

Figure S6. Expression of CSC markers (CD133 and CD44) for breast cancer cells cultured on gradient gels with or without inhibitors and root mean square deviation (RMSD) of the results. $(\mathrm{N}=3)$ 